\title{
Modernidade e Racionalização: Entre a Tragédia do Esclarecimento e a Esperança no Agir Comunicativo
}

\author{
Renan Oliveira de Carvalho \\ Recebido em setembro de 2020 \\ Aceito em dezembro de 2020
}

\section{RESUMO}

O presente trabalho tem como objetivo analisar a perspectiva de autores que construíram suas teorias da Modernidade a partir do paradigma da racionalização. Para isso, pretende-se lançar um olhar para as teorias de sociólogos como Weber, Adorno, Horkheimer e Habermas, e suas diferentes perspectivas acerca do tema. O que se pretende nas páginas que seguem é apresentar as diferentes teorias da Modernidade dos autores em questão e refletir sobre suas perspectivas, diagnósticos e projeções em torno da percepção de que a Modernidade é fruto de um processo de racionalização da vida e do mundo pelo qual passou a sociedade ocidental.

Palavras chave: Modernidade; Racionalização; Adorno; Horkheimer; Habermas.

\section{Modernity and Rationalization: Between the Tragedy of Enlightenment and the Hope in Comunicative Action.}

\begin{abstract}
This paper aims to analyse the perspective of authors that built their theory of modernity from the rationalization paradigm. To accomplish that, its intents to present the theory of sociologists as Weber, Adorno, Horkheimer and Habermas, and their different perspectives about the subject. What is intended in the following pages is to present their theories about modernity, and from that reflect on their perspectives, diagnoses and projections around the perception that modernity is the result of a process of rationalization of life and the world that Western society has gone through.
\end{abstract}

Keywords: Modernity; Rationalization; Adorno; Horkheimer; Habermas.

\section{Introdução}

$\mathrm{O}$ processo de desenvolvimento das sociedades modernas levou diversos autores da sociologia - e das ciências humanas em geral - a tentar compreender esse fenômeno. Afinal, o que definiria a Modernidade? Qual seria sua característica distintiva que

\footnotetext{
${ }^{1}$ Bacharel em Direito pela UFRJ e licenciado em Ciências Sociais também pela UFRJ. Mestre em Ciência Política pela UFF. Doutorando em Sociologia pelo IESP-UERJ. Bolsista CAPES. Contato: reenan.carvalho@gmail.com.
} 
permitiria separar a época moderna daquilo que se convencionou chamar de Idade Média?

O conceito de Modernidade refere-se a um conjunto de fenômenos que se estabeleceram e se desenvolveram cumulativamente, reforçando-se mutuamente num processo de grandes transformações sociais que tornaram possível a conformação de uma nova realidade social. Dentre os acontecimentos fundamentais que contribuíram para a conformação da Modernidade, podemos citar: A formação de capital, o processo de industrialização, o desenvolvimento das forças produtivas e o aumento da produtividade do trabalho; o estabelecimento do Estado-nação, a centralização do poder estatal e o surgimento de sua burocracia; a expansão dos direitos individuais e da participação política; o surgimento das grandes metrópoles e das formas urbanas de vida; o desenvolvimento da ciência, da escolarização formal e a secularização de valores e normas (HABERMAS, 2000).

Muitas foram as chaves interpretativas utilizadas na tentativa de apreender o desenvolvimento daquilo que se convencionou chamar de Modernidade. Segundo Habermas (2000), o primeiro filósofo a desenvolver um conceito claro de Modernidade foi Hegel, para quem o princípio dos "novos tempos" seria a subjetividade. Na sociologia, Marx identifica a Modernidade com o capitalismo, apontando também a importância da razão para a conformação e superação das contradições existentes nessa nova sociedade; Durkheim, a percebe como fruto de um processo de diferenciação funcional que transformou cabalmente as estruturas da sociedade; Tocqueville vislumbra a igualdade como a característica distintiva da Modernidade, identificando-a como caminho pelo qual as sociedades tenderiam a seguir nesses "novos tempos"; já para o historiador Reinhart Koselleck, a Modernidade poderia ser percebida como uma nova temporalidade histórica, identificada através da percepção de um progressivo distanciamento entre o espaço de experiência do passado e o horizonte de expectativa do futuro.

Neste artigo buscarei explicitar a perspectiva teórica acerca da Modernidade em alguns autores que analisaram o fenômeno do seu advento a partir do paradigma da racionalização. Para isso, a primeira parte deste trabalho traz as contribuições do primeiro autor a formular este prisma para a análise daquilo que se convencionou 
chamar de Modernidade, Max Weber. Ao trazer sua percepção da Modernidade como racionalização, Weber cria uma nova forma de abordagem deste fenômeno que, como veremos, iria posteriormente influenciar grandes sociólogos e filósofos do século XX.

Em seguida, o artigo analisa o trabalho de Theodor Adorno e Max Horkheimer, principalmente no que tange às reflexões realizadas na obra intitulada "Dialética do Esclarecimento" e a angústia e o mal-estar que este escrito carrega. É nesta oportunidade que os autores desenvolvem em conjunto suas perspectivas acerca da Modernidade, descrevendo-a como a "consagração" de um processo de esclarecimento, pelo qual a humanidade já vinha percorrendo desde os tempos helenísticos até o iluminismo, e que sob a ótica destes autores, produziu efeitos terríveis que culminaram em tragédias humanitárias que se manifestaram por meio de acontecimentos marcantes e dolorosos como as duas grandes guerras, o totalitarismo estatal e o holocausto. Neste sentido, o artigo percebe as reflexões de Adorno e Horkheimer como um desenvolvimento e superação da teoria de Weber sobre a Modernidade, e como uma reafirmação - com maior ênfase, tendo em vista justamente os acontecimentos do século XX testemunhados por eles - do mal-estar que engendra o processo de racionalização e o desenvolvimento da Modernidade.

Por fim, o trabalho traz ao debate as contribuições de Jürgen Habermas, com suas reflexões sobre a Modernidade que deságuam em sua Teoria do Agir Comunicativo. A partir da exposição e discussão acerca dos principais elementos de sua teorização sobre a Modernidade e de sua Teoria do Agir Comunicativo, pretendo identificar os elementos desenvolvidos pela teoria de Habermas que o permitem buscar a superação dos impasses e o enfrentamento dos fantasmas detectados por Weber, Adorno e Horkheimer nos processos de conformação e desenvolvimento da Modernidade. O autor intenta com isso redefinir a própria Teoria Crítica formulada pelos autores da primeira geração da Escola de Frankfurt. Para isso, Habermas recorre a formulação de um arcabouço teórico que denota a esperança de que o processo de racionalização poderia, por meio da ação comunicativa, trazer o entendimento entre as pessoas e os povos, substituindo as ações fundadas na racionalidade instrumental em favor de sociabilidade pautada na comunicação, com vistas a reorientar as interações entre os indivíduos na busca pelo entendimento. 


\section{Max Weber e a Modernidade como Racionalização²}

Max Weber foi sem dúvidas o principal dos sociólogos tidos como um dos "clássicos da sociologia" a analisar e descrever a Modernidade a partir do paradigma da racionalização - ao menos de forma mais explícita e sistemática. ${ }^{3}$ Para Weber a característica distintiva da Modernidade seria o processo de racionalização da vida e desencantamento do mundo que as sociedades ocidentais haviam experimentado. Em linhas gerais, entende-se que o conceito de racionalização, como utilizado por Weber, significa a redução à racionalidade de todos os aspectos da vida social. Quando trata do processo de racionalização da vida, o autor busca descrever o processo por meio do qual, nas sociedades ocidentais, as ações sociais dos indivíduos passam a ser orientadas não mais a partir de motivações tradicionais e afetivas - baseadas nos costumes, tradições ou sentimentos - mas a partir de uma lógica estritamente racional, seja quanto aos valores ou, principalmente, em relação aos fins (WEBER, 1994). 4

Sobre o processo de racionalização em Weber, Habermas escreve:

O que Max Weber descreveu do ponto de vista da racionalização não foi apenas a profanação da cultura ocidental, mas, sobretudo, o desenvolvimento das sociedades modernas. [...] Weber entende esse processo como a institucionalização de uma ação econômica e administrativa racional com respeito a fins. À medida que o cotidiano foi tomado por esta racionalização cultural e social, dissolveram-se também as formas de vida tradicionais, que no início da modernidade se diferenciaram principalmente em função das corporações de ofício (HABERMAS, 2000, p. 3).

\footnotetext{
${ }^{2}$ Esta seção é uma versão modificada da seção de mesmo nome contida no artigo: CARVALHO, R. O. de. A modernidade nos clássicos da sociologia: percepções acerca do mundo moderno em Tocqueville, Durkheim e Weber, Sociologias Plurais, v.5 n.2, p. 194-211, dez 2019.

3 Antes dele podemos perceber em Marx uma aproximação a essa abordagem, porém, de forma mais residual e não sistemática - estando o conceito de racionalização em meio a sua teoria do capitalismo e da revolução. Marx percebia de forma positiva os avanços que poderiam ser aferidos com o progresso da razão e da técnica, e buscava, a partir de sua teoria da luta de classes e de suas projeções acerca de uma futura sociedade comunista, imaginar um mundo onde a racionalidade conformasse uma sociedade onde a humanidade tomasse as rédeas do seu próprio destino, sem a necessidade da dominação do homem pelo homem.

4 Nesse sentido, a racionalização ofereceria as condições nas quais a ação social é exercida. A racionalização é o processo que confere significado à diferenciação entre as linhas de ação.
} 
Um processo análogo ao de racionalização e - em parte 5 - concomitante a ele que também é fundamental para análise weberiana da Modernidade, é aquilo que Weber conceitua como processo de "desencantamento do mundo". Com o processo de desencantamento, cada vez mais as sociedades ocidentais deixam de conceber o mundo como permeado por forças ocultas que podem ser manipuladas através de rituais e feitiços, e passam a repudiar e perseguir a prática da magia, que começa a ser percebida como superstição e sacrilégio (WEBER, 2004, p. 96). Tal processo se desenvolve desde a conformação do pensamento científico-filosófico do período helenístico e tem seu apogeu com o protestantismo ascético, que, segundo Weber (2004), tem grande influência na conformação do capitalismo e da Modernidade.

É na obra "A ética protestante e o "espírito" do capitalismo", que Weber vai buscar demonstrar como uma conjunção de fatores estabelecidos por determinadas denominações protestantes convergiram de forma a proporcionar condições favoráveis ao desenvolvimento do capitalismo na Europa Ocidental. As afinidades eletivas existentes entre certas práticas e ideias conformadas pelo protestantismo do calvinismo e de outras orientações "puritanas" - tais quais a angústia pela salvação trazida pela doutrina teológica da predestinação, os elementos que identificavam a ética do trabalho e a vocação profissional como formas de glorificar a Deus e o ascetismo como forma de condução da vida cotidiana - ensejaram, ao longo do tempo, tanto um processo de acumulação de capital, quanto o surgimento de um "espírito do capitalismo". 6 "Essa racionalização da conduta de vida no mundo, mas de olho no Outro Mundo é o efeito da concepção de profissão do protestantismo ascético” (WEBER, 2004, p. 139). Neste sentido, para Weber, os processos de racionalização da vida e desencantamento do mundo estariam profundamente imbricados, sendo ambos fundamentais para a

\footnotetext{
${ }^{5}$ Em parte, pois o processo de desencantamento do mundo seria anterior a este processo de racionalização da vida no mundo ocidental. Uma vez que, como visto, tem início ainda na antiguidade com a conformação das religiões judaicas e prossegue até a Modernidade. De certo modo, o processo de racionalização é também anterior ao advento da Modernidade, uma vez que não se pode dissociá-lo completamente do desencantamento do mundo. O que é característico da Modernidade é a predominância cada vez mais acentuada de uma racionalidade instrumental, ligada a ação social com relação aos fins.

${ }^{6}$ Por "espírito do capitalismo", devemos entender a conformação de um "ethos", "uma ideia do dever que tem o indivíduo de se interessar pelo aumento de suas posses com um fim em si mesmo" que se conforma assumindo "o caráter de uma máxima de conduta de vida eticamente coroada" (Weber, 2004, p. 45).
} 
conformação daquilo que entendemos como Modernidade.

\begin{abstract}
A intelectualização e a racionalização geral não significam, pois, um maior conhecimento geral das condições da vida, mas algo de muito diverso: o saber ou a crença em que, se alguém simplesmente quisesse, poderia, em qualquer momento, experimentar que, em princípio, não há poderes ocultos e imprevisíveis, que nela interfiram; que, pelo contrário, todas as coisas podem - em princípio - ser dominadas mediante o cálculo. Quer isto dizer: o desencantamento do mundo. Diferentemente do selvagem, para o qual tais poderes existem, já não temos de recorrer a meios mágicos para controlar ou invocar os espíritos. Isso consegue-se graças aos meios técnicos e ao cálculo. Tal é, essencialmente, o significado da intelectualização (WEBER, 2010, p. 30-31).
\end{abstract}

Portanto, é através do paradigma da racionalização que Weber busca entender e explicar ao longo de suas obras os processos de transformação que ensejaram a conformação de realidades até então inéditas como o desenvolvimento das ciências, a industrialização, o surgimento do Estado moderno e sua centralização, a formação de sua burocracia e até a própria formação da sociedade capitalista. Através de seus escritos podemos perceber sua posição acerca da tendência ao aprofundamento destes processos, percebendo-os como quase inevitáveis e alertando para a falta de sentido e o mal-estar que poderiam ensejar à existência do homem moderno. A ideia de que na Modernidade o ser humano estaria preso a uma "jaula de ferro" - na célebre tradução de Talcott Parsons - , ou em uma “crosta de aço", que nos prenderia a uma lógica que percebe a acumulação de bens materiais como o fim último da existência e, com isso, negaria ao ser humano a possibilidade de atribuir outros sentidos a sua própria existência, é expressão de seu pessimismo com a Modernidade (WEBER, 2004, p. 165).

\footnotetext{
Ninguém sabe ainda quem no futuro vai viver sob essa crosta e se ao cabo do desenvolvimento monstro hão de surgir profetas inteiramente novos [...] Então, para os 'últimos homens' desse desenvolvimento cultural, bem poderiam tornar-se verdades as palavras: "Especialistas sem espírito, gozadores sem coração: esse Nada imagina ter chegado a um grau de humanidade nunca antes alcançado" (WEBER, 2004, p. 166, grifo do autor).
}

Weber nos dá elementos para perceber na racionalização um processo cujo aprofundamento possibilita a conformação de mudanças materiais e culturais na sociedade, mas que ao mesmo tempo ensejam certo "aprisionamento" da subjetividade 
humana. ${ }^{7}$ Nesse sentido, podemos perceber que apesar da Modernidade conformar um tempo de mudança social e de ruptura com as "amarras" da tradição, esta ruptura parece se efetivar à custa ou a despeito da liberdade humana.

Ao estabelecer uma concepção do capitalismo como "cultura” — identificando a conformação de um "espírito do capitalismo", ou seja, uma forma de ser eminentemente capitalista - e perceber na racionalização o elemento fundamental a caracterizar a Modernidade, Weber nos fornece importantes contribuições para interpretar esses "novos tempos”. É a partir de suas reflexões que diversos autores buscaram também teorizar sobre a Modernidade, seja na busca por avançar em seus achados, ou na tentativa de superar esse paradigma com vistas à construção de novas teorias e reflexões acerca da Modernidade.

\section{Adorno e Horkheimer e a tragédia do esclarecimento}

Theodor Adorno e Max Horkheimer vão além do diagnóstico de Weber acerca do mal-estar que engendra o processo de racionalização e o desenvolvimento da Modernidade. Suas análises - que buscam conformar um campo da teoria social denominado Teoria Crítica - dão conta não só da perda de sentido que o advento de uma forma de vida calcada na racionalidade instrumental teria gerado, mas da derrocada do processo de esclarecimento ${ }^{8}$ pelo qual a sociedade ocidental teria passado desde sua "constituição" - ainda na antiguidade - , e que teria levado o ser humano a objetificar e dominar a natureza, para, a partir daí, estabelecer uma estrutura de dominação e subjugação do homem pelo homem nunca antes vista na história da humanidade. Segundo esses autores, fundadores da Escola de Frankfurt, o projeto do esclarecimento e a consequente constituição da Modernidade teriam levado a humanidade a um ponto de calamidade social, que pode ser percebido quando observamos a conformação de realidades sociais novas que vão desde o estabelecimento do terror do nazismo e do holocausto, do totalitarismo estatal - de esquerda e de direita - e das demais formas

\footnotetext{
7 E para isso, a utilização da metáfora da "jaula de ferro" ou "crosta de aço" - conforme as diferentes traduções - é realmente ilustrativa.

${ }^{8}$ Por vezes também traduzido como "Ilustração", o conceito de esclarecimento em Adorno e Horkheimer se refere tanto ao iluminismo quanto ao processo de racionalização já salientado por Weber em sua obra.
} 
de controle e dominação desenvolvidas com o advento da Modernidade.

Como bem observa José Maurício Domingues:

Seus escritos exalam um desespero e uma asfixia que não são difíceis de compreender, se nos pusermos naquela conjuntura, no dizer de Hannah Arendt, de "tempos sombrios", com o stalinismo de um lado, o nazismo e o fascismo do outro, e ainda com a expansão que perceberam como assustadora da cultura de massas nos Estados Unidos (DOMINGUES, 2001, p. 73).

Assim como Weber remete os processos de racionalização e desencantamento do mundo ao período helenístico, com a conformação do pensamento científico a partir da filosofia, Adorno e Horkheimer identificam o "surgimento" do esclarecimento como tendo se dado na mesma época, e entendem o processo de esclarecimento como sendo a "superação" do mito. Na verdade, para esses autores da primeira geração da Escola de Frankfurt, a constituição do próprio mito já consistia em uma primeira fase do processo de esclarecimento. 9 Isto pelo fato de que o mito já pretendia relatar os fatos, dizer a origem das coisas e explicar a realidade, ou seja, dar inteligibilidade ao mundo. "O mito converte-se em esclarecimento, e a natureza em mera objetividade" (ADORNO; HORKHEIMER, 1985, p. 21).

Segundo Adorno e Horkheimer o conceito de esclarecimento designa o processo segundo o qual os homens passam a se utilizar da razão para dominar a natureza e superar o medo do desconhecido. Consiste num processo de separação do homem em relação à natureza para melhor "compreendê-la”. Leia-se, classificá-la, dominá-la e instrumentalizá-la através da razão. ${ }^{10}$ Separação entre o homem e a natureza, do sujeito cognoscente frente ao objeto cognoscível. É o processo do esclarecimento que, segundo esses autores, vai tornar possível todo o progresso técnico e científico observado desde o fim da Idade Média, fenômeno que produziu tantas transformações na sociedade, como a industrialização, a burocratização, e a economia de mercado.

No sentido mais amplo do progresso do pensamento, o esclarecimento tem perseguido sempre o objetivo de livrar os homens do medo e investi-los na

\footnotetext{
9 "Mas os mitos que caem vítimas do esclarecimento já eram produto do próprio esclarecimento". (ADORNO; HORKHEIMER, 1985).

${ }^{10}$ Vale salientar aqui que a razão a que Adorno e Horkheimer se referem ao tratar do tema é a razão instrumental, ou seja, aquela razão finalística ou teleológica, já criticada por Weber como a forma prevalecente da racionalidade no processo de racionalização da vida na Modernidade.
} 
posição de senhores. Mas a terra totalmente esclarecida resplandece sob o signo de uma calamidade triunfal. O programa do esclarecimento era o desencantamento do mundo. Sua meta era dissolver os mitos e substituir a imaginação pelo saber (ADORNO; HORKHEIMER, 1985, p. 19).

Entretanto, segundo os autores: "O preço que os homens pagam pelo aumento do seu poder é a alienação daquilo sobre o que exercem poder. O esclarecimento comporta-se com as coisas como o ditador comporta-se com os homens" (ADORNO; HORKHEIMER, 1985, p. 21). O esclarecimento é também o processo por meio do qual se conforma uma nova subjetividade, a do homem capitalista, que se expressa essencialmente através de um individualismo existencial, de uma ética utilitarista e do cálculo racional como fundamento de sua ação social.

Para Adorno e Horkheimer, em escritos diversos e formas diferentes o sistema
capitalista, a forma de organização daquele modo de produção, atomizava as
pessoas, as quais, buscando seus fins utilitários individuais, acabavam
prisioneiras da própria lógica do capital. Transformando as relações sociais em
fenômenos objetivos e abstratos que escapavam ao controle e mesmo à
consciência das pessoas - em outras palavras, que reificavam as interações
humanas - o capitalismo tolhia a liberdade do sujeito. [...] Fazendo uso de sua
razão individual, os indivíduos conseguiam de fato impulsionar o controle da
espécie sobre a natureza. A contrapartida disso, entretanto era um controle
também crescente dos indivíduos uns sobre os outros (DOMINGUES, 20o1, p.
$75-77$ ).

Segundo Adorno e Horkheimer (1985, p.20), "O que os homens querem aprender da natureza é como empregá-la para dominar completamente a ela e aos homens. Nada mais importa”. É essa nova subjetividade do homem capitalista, que se conforma através do esclarecimento e vai produzir a tragédia social da Modernidade a qual os autores da Escola de Frankfurt buscam denunciar. Pois a razão instrumental e o individualismo, utilizados para o exercício da dominação do homem pelo homem vão produzir efeitos nunca imaginados. As experiências do nazismo e do fascismo seriam a expressão máxima do horror racionalizado. O holocausto se mostra como processo que consagra a racionalização da barbárie. Isto porque utiliza de métodos e procedimentos organizacionais para, em primeiro lugar, arrancar de milhões de pessoas sua força de trabalho escravizada com vistas a suprir a máquina de guerra e o capitalismo alemão. Em um segundo momento, são essas pessoas que - após chegarem a um nível inimaginável de desgaste físico e existencial sob as condições de trabalhos forçados nos 
campos de concentração - serão vítimas de uma verdadeira indústria da morte construída com objetivo de dizimar populações inteiras.

A perseguição e o extermínio também foram experimentados sob o stalinismo, sepultando as esperanças de grande parte dos marxistas na conquista da liberdade humana através da formação de uma sociedade comunista esclarecida e livre da alienação produzida pelo modo de produção capitalista. Entretanto, é a emergência do poder da burocracia e seus efeitos no controle da vida dos indivíduos pelo Estado que se faz sentir. Da mesma forma, o esclarecimento traz consigo a emergência da indústria cultural nos Estados Unidos e a dominação através da reprodução cultural totalmente racionalizada, padronizada e escravizante. Ou seja, a razão e a técnica usadas como elementos de dominação e sujeição de indivíduos que creem serem livres mesmo sendo dominados.

Segundo Marcos Nobre (2008, p.47), "Na Dialética do esclarecimento, o que se encontra é o "mundo administrado", uma forma sofisticada de controle social de que as massas são inteiramente excluídas e sobre a qual não tem qualquer tipo de domínio”. Seria justamente esse "mundo administrado" ", conceito que busca reelaborar as contribuições teóricas de Friedrich Pollock — que em suas pesquisas teria apontado para mudanças estruturais no funcionamento do capitalismo, por meio das quais teria se conformado uma nova fase do capitalismo, o "capitalismo de Estado", onde haveria a preponderância cada vez maior da intervenção e do planejamento estatal na condução da economia e, com isso, uma primazia cada vez maior da política estatal sobre a sociedade -, o que dificultaria a ação social com vistas a emancipação.

Isto porque, diferentemente de Pollock, Adorno e Horkheimer não acreditavam na possibilidade de controle democrático popular efetivo sobre as estruturas burocráticas que organizavam essa nova conformação da sociedade capitalista. $\mathrm{O}$ controle social efetivado pelas estruturas desse mundo administrado seria orientado pela racionalidade instrumental, que direciona o aparato burocrático com vistas a reprodução da sociedade capitalista e das formas de dominação que lhe são próprias. Seria através do planejamento e da intervenção do Estado nos domínios da economia,

"Também denominado de “capitalismo administrado”, ou ainda, “capitalismo tardio”. 
da política e da sociedade como um todo, agindo tanto para dirimir as possíveis causas de insurreições e estabilizar os elementos disruptivos do capitalismo, ${ }^{12}$ quanto para reforçar sua lógica,13 que o "capitalismo administrado" bloquearia as possibilidades de sua superação. "O capitalismo administrado é um sistema que se fecha sobre si mesmo, que bloqueia estruturalmente qualquer possibilidade de superação virtuosa da injustiça vigente e paralisa, portanto, a ação genuinamente transformadora” (NOBRE, 2008, p. 47).

\begin{abstract}
Por isso, Horkheimer e Adorno empreenderam, na Dialética do esclarecimento, uma investigação sobre a razão humana de amplo espectro. Seu objetivo foi o de buscar compreender por que a racionalidade das relações sociais humanas, ao invés de levar à emancipação, à instauração de uma sociedade de homens livres e iguais, acabou por produzir um sistema social que bloqueou estruturalmente qualquer possibilidade emancipatória, transformando os indivíduos em engrenagens de um mecanismo que não compreendem e não dominam e ao qual se submetem e se adaptam impotentes. Esse problema mais geral se traduz na tarefa de compreender como a razão humana acabou por restringir-se historicamente à sua forma instrumental, cuja forma social concreta é a do mundo administrado (NOBRE, 2008, p. 50).
\end{abstract}

Essa seria a tragédia do esclarecimento a qual Adorno e Horkheimer se referem. Nesse sentido, vão além de Weber na crítica à razão instrumental, que sobre a forma do esclarecimento se torna totalitária, abrangendo todos os aspectos da vida e produzindo os resultados aqui apresentados. Não é apenas a descrença com o que está por vir, mas a constatação de que o processo do esclarecimento nos legou um período de "tempos sombrios", onde as mazelas sociais não são apenas projeções descrentes sobre um futuro nebuloso, mas constatações de um presente cuja realidade se mostra trágica.

\footnotetext{
${ }^{12}$ Como exemplo, temos o controle do governo sobre os sistemas de crédito e comércio exterior, as ações empreendidas pelo Estado para evitar ou superar as crises econômicas, as polícias e departamentos de inteligência empenhados em desarticular grupos ou movimentos de oposição ao sistema e as políticas de assistência social que visam atenuar os efeitos da exclusão econômica e social conformados pelas contradições próprias do capitalismo.

${ }^{13}$ Entre os mecanismos desse mundo administrado que contribuem decisivamente para esse "reforço da lógica" do capital, ou mesmo para conformação de uma subjetividade humana eminentemente capitalista está a indústria cultural. Fenômeno que designa o processo de padronização e racionalização tanto do processo produtivo quanto da difusão de bens culturais - através do cinema, do rádio, da televisão e da imprensa - observado pelos autores nas sociedades modernas, que teria o efeito de homogeneizar a cultura, e através dela, a própria consciência das pessoas. Ao implementar a lógica da produção em massa da fábrica e do sistema capitalista para o campo da cultura, a indústria cultural se estabelece como instrumento fundamental empregado para reproduzir a ideologia do sistema e integrar os indivíduos à sua lógica.
} 


\section{Jürgen Habermas e a Esperança no Agir Comunicativo}

É a partir da busca pela superação dos impasses e enfrentamento dos fantasmas detectados por Weber, Adorno e Horkheimer nos processos de conformação e desenvolvimento da Modernidade, bem como, na tentativa de renovar a Teoria Crítica formulada pelos dois últimos que Jürgen Habermas construiu boa parte de sua obra. Para elaboração de sua síntese teórica, melhor sistematizada em seu livro de 1981, "Teoria do Agir Comunicativo", Habermas vai se utilizar de um amálgama de autores e teorias. Mead e sua psicologia social interacionista; Durkheim e a sociologia funcionalista; Schütz e sua fenomenologia; Parsons e sua teoria dos sistemas de ação; Luhmann e sua teoria dos sistemas autorregulados; são algumas das principais referências utilizadas pelo autor, assim como Marx, Weber, Piaget, e os já citados, Adorno e Horkheimer.

No cerne de suas contribuições teóricas, está a busca pela construção de um novo paradigma que dê conta de superar as análises sobre a Modernidade que se fundam exclusivamente na crítica à razão instrumental - uma vez que a racionalidade instrumental não seria a única forma de racionalidade existente. Para isso, Habermas formula um novo conceito, o de racionalidade comunicativa, através do qual buscará tanto desenvolver sua análise sobre a Modernidade quanto escapar das conclusões e projeções absolutamente pessimistas sobre ela formuladas pelos autores aqui trabalhados.

\footnotetext{
Acredita Habermas que, desde Marx, passando por Simmel, Weber e Lukács, e chegando a Adorno e Horkheimer, a razão tem sido concebida como basicamente instrumental e referida ao indivíduo em si, ou então objetificado em relações sociais reificadas. Habermas aceita, em parte, essa postulação e o diagnóstico que veria na modernidade a apoteose da razão instrumental, conceituando, em compensação uma outra racionalidade, a comunicativa (DOMINGUES, 2001, p. 83).
}

Segundo Habermas, a racionalidade comunicativa se constitui socialmente por meio do processo de interação dialógica entre atores presentes em uma situação social. Nesse sentido, diferentemente da racionalidade instrumental, percebida como uma faculdade humana onde o indivíduo é considerado isoladamente frente à realidade que 
o cerca, a racionalidade comunicativa seria um processo interativo e constituído socialmente a partir de situações sociais onde os indivíduos realizam um procedimento cognitivo de natureza intersubjetiva. Neste processo, os atores em comunicação buscam chegar a um entendimento quanto a pretensões de validade criticáveis de suas afirmativas. É por meio dessa racionalidade dialógica, que vai se orientar na busca pelo entendimento, que se estrutura o que Habermas chama de "ação comunicativa”. A ação comunicativa consiste justamente nessa interação dialógica na busca pelo entendimento onde os atores vão buscar não o sucesso individual na interação, mas a harmonizar seus planos de ação sobre as bases de uma definição comum de situação.

Entre os conceitos mais importantes para se entender a sua Teoria do Agir Comunicativo temos o conceito de mundo da vida. Oriundo da fenomenologia de Schütz, o conceito de mundo da vida em Habermas designa um saber implícito acerca do mundo, sobre o qual nós não temos acesso imediato uma vez que é pré-reflexivo e não problemático. Seria como um ambiente, ou um horizonte dentro do qual as interações se estabelecem, uma vez que ele é compartilhado pelos atores como uma realidade auto evidente. Como nos ensina Domingues (2001, p.87): "Para Habermas o sujeito individual é estruturado interativamente no mundo da vida, no curso de sua socialização”. Dessa forma, o mundo da vida pode ser considerado como a base ou o solo a partir do qual toda ação comunicativa vai se estabelecer. O mundo da vida seria formado por três elementos, que poderiam ser designados como: "cultura”, "sociedade” e "pessoa”. Por "cultura”, podemos entender que seria o conjunto de símbolos comuns aos indivíduos, ou estoque de conhecimentos compartilhados aos quais os atores recorrem quando buscam compreender algo no mundo. "Sociedade" aqui designa o conjunto de comportamentos regularizados e socialmente sancionados (DOMINGUES, 2001, p. 85). Já no que tange ao elemento que se refere à "pessoa”, entendemos que Habermas designa o processo de socialização e formação da personalidade dos indivíduos, onde estes adquirem as competências necessárias para agir em sociedade.

Sob o aspecto funcional do entendimento, o agir comunicativo se presta à transmissão e à renovação de um saber cultural; sob o aspecto da coordenação da ação, ele possibilita a integração social e a geração de solidariedade; e, sob o aspecto da socialização, o agir comunicativo serve à formação de identidades pessoais. [...] A esses processos de reprodução cultural, de integração social e 
de socialização correspondem, enquanto componentes estruturais do mundo da vida, a cultura, a sociedade e a pessoa (HABERMAS, 2012, p. 252).

Concomitante a ação comunicativa estaria à ação instrumental e a ação estratégica, conformadas pela racionalidade instrumental. Por meio dela, realizamos nosso intercâmbio com a natureza e com os demais indivíduos de forma a alcançar nossos objetivos individuais na interação. Segundo Domingues (2001), esses aspectos da racionalidade humana estariam reservados aqueles sistemas de ação social nos quais nós tratamos os outros como meios para atingir fins, sem considerações mais reflexivas em relação à humanidade ou a individualidade daqueles com quem interagimos. Habermas interpreta o capitalismo - tido aqui como a sociedade de mercado ou sistema econômico - e o Estado moderno como subsistemas que se diferenciam dos componentes sociais do mundo da vida através dos meios “dinheiro" e "poder". Segundo o autor, é através da institucionalização das atividades econômicas e administrativas que se conforma um processo mediante o qual os meios "dinheiro" e "poder" se ancoram no mundo da vida. Inicialmente, esses sistemas autorregulados cumprem uma função de mediar as interações comunicativas entre os indivíduos, cada vez mais sobrecarregadas em razão da crescente complexificação de uma sociedade cada vez mais diferenciada.

\begin{abstract}
À medida que os meios do dinheiro e do poder permitem aos subsistemas da economia e do Estado se diferenciar de um sistema de instituições inserido no mundo da vida, despontam esferas de ação organizadas formalmente, não mais integradas pelo mecanismo do entendimento, as quais irão se destacar dos contextos do mundo da vida, cristalizando-se numa espécie de sociedade sem normas. As novas organizações geram perspectivas sistêmicas, à luz das quais o mundo da vida é percebido como algo distanciado e confuso, que não se distingue dos componentes do respectivo entorno. Elas se tornam autônomas mediante uma delimitação neutralizadora, que se contrapõe às estruturas simbólicas do mundo da vida; e nesse processo elas se tornam indiferentes em relação à cultura, à sociedade e à personalidade (HABERMAS, 2012, p.556).
\end{abstract}

Entretanto, com o tempo, esses sistemas passam a ganhar cada vez mais preponderância em relação ao mundo da vida estruturado simbolicamente, e não só se destacam dele como o relegam a um "segundo plano". Dessa forma, um agir teleológico orientado pelo sucesso e controlado pelos cálculos egocêntricos do lucro e com vistas à consecução de fins individuais ganha cada vez mais preponderância em face do agir orientado pelo entendimento. É nesse sentido que Habermas (2012, p. 355) vai afirmar 
que "a partir daí, a mediatização do mundo da vida se transforma em colonização".

Seria justamente essa colonização do mundo da vida pelos sistemas do "poder" e do "dinheiro" que estaria levando a sociedade às patologias sociais severas observadas na Modernidade, "uma vez que a cultura, as instituições e a personalidade só podem reproduzir-se por intermédio do mundo da vida e da ação comunicativa” (DOMINGUES, 2001, p. 89).

\begin{abstract}
As ações comunicativas não constituem apenas processos de interpretação em que um saber cultural é submetido a um "teste no mundo"; elas significam também processos de socialização e de integração social. [...] Quando os participantes da interação, voltados "ao mundo", reproduzem, mediante suas realizações de entendimento, o saber cultural do qual se nutrem, eles reproduzem ao mesmo tempo sua identidade e sua pertença a coletividades (HABERMAS, 2012, p. 255).
\end{abstract}

As esperanças de Habermas na solução das patologias sociais percebidas na Modernidade seriam, portanto, depositadas em uma sociedade cada vez mais orientada pelo agir comunicativo. "Habermas acredita haver um potencial cognitivo e sobretudo moral mais reflexivo e universalista - disponível nas estruturas de consciência contemporâneas - e, portanto, mais avançado que aquele incorporado nas instituições sociais.” (DOMINGUES, 2001, p. 89). Faltariam, porém, em sua avaliação, atores coletivos capazes de colocar em prática esse projeto. Por essa razão, suas investigações e formulações teóricas passam a se dirigir para os conceitos de democracia deliberativa e de esfera pública, além de se direcionarem também para o conteúdo emancipador do direito - principalmente como meio de expressar e consagrar institucionalmente o resultado de deliberações livres de coerção efetuadas através da esfera pública —, na busca de imaginar soluções para as questões sociais que afligem a sociedade na Modernidade do capitalismo tardio. "Em correspondência com isso, direito e democracia se tornam, no decorrer da obra de Habermas, principalmente a partir do final dos anos 1980, temas cada vez mais centrais” (NOBRE, 2008, p.126).

Neste sentido, em obras mais tardias ${ }^{14}$ Habermas passa a considerar que o direito poderia cumprir a função de mediar as relações entre o mundo da vida e os

\footnotetext{
${ }^{14}$ Como na obra intitulada "Direito e democracia: entre a facticidade e validade", de 1992.
} 
sistemas funcionais do "dinheiro" e do "poder", uma vez que em sua estrutura estariam presentes tanto a racionalidade instrumental — através de sua utilização como meio de se atingir objetivos - quanto a comunicativa - uma vez que o debate e o discurso, e, portanto, a ação comunicativa, são elementos constitutivos do direito. ${ }^{15}$ Para que se possa alcançar esse resultado, entretanto, é fundamental a existência de um ambiente livre de coerções na esfera pública, onde se possa debater livremente as ideias na busca pelo consenso, garantindo assim a legitimidade das deliberações - e do próprio direito.

Só através de uma sociedade que estimule a busca pelo consenso, através de uma forma de sociabilidade mais pautada no diálogo e na argumentação com vistas a chegar ao entendimento que, com o tempo, o agir comunicativo poderia retomar o espaço perdido pela colonização dos sistemas autorreferidos do "poder" e do "dinheiro" e passar a reorientar as interações entre os indivíduos na busca pelo entendimento, reordenando assim a sociedade.

\section{Considerações finais}

A perspectiva que interpreta a constituição e o desenvolvimento da Modernidade a partir do paradigma da racionalização orientou diferentes autores a formularem teorias que - apesar de compartilharem em muitos aspectos certos princípios fundamentais - variam bastante entre si. Em um primeiro momento, marcado por um pessimismo resignado e descrente em relação ao presente e ao futuro nas penas de Weber, Adorno e Horkheimer, a racionalidade é vista não só como elemento fundamental a possibilitar as transformações técnicas e sociais que vão dar emergência à Modernidade, mas também, e principalmente, ${ }^{16}$ como a origem das mazelas e da tragédia que resultou da conformação desses "novos tempos".

Já em um segundo momento, a racionalidade é “dividida” entre racionalidade instrumental e racionalidade comunicativa, com vistas a formular uma teoria social capaz de superar a descrença em relação às patologias sociais percebidas na

\footnotetext{
${ }^{15}$ Estando presentes tanto em sua elaboração através dos debates legislativos - que por sua vez são influenciados pelo debate existente na esfera pública — quanto na prática judiciária.

${ }^{16}$ No caso de Adorno e Horkheimer.
} 
Modernidade. É através da esperança utópica na potencialidade do uso da razão na estruturação de uma sociedade pautada na busca do consenso por meio da crítica argumentativa e do diálogo que Habermas vai tentar renovar a Teoria Crítica e resolver o "nó teórico" deixado por Adorno e Horkheimer.

As novas tecnologias e novas formas de sociabilidade que elas ensejam tem renovado as possibilidades de mobilização do paradigma da racionalização como prisma de interpretação o mundo, ${ }^{17}$ tanto no que tange a percepção de que, através do avanço da tecnologia, estamos caminhando para um mundo cada vez mais dominado pela racionalidade instrumental - pensemos nas possibilidades de controle social por parte do Estado e de corporações privadas advindas dos dados coletados pelos aplicativos instalados nos dispositivos móveis que cada vez mais fazem parte da vida dos indivíduos, e dos quais o sistema de crédito social chinês é o "tipo ideal" mais assustador — quanto ao que se refere às possibilidades abertas à ação comunicativa e ao livre debate de ideias com essa nova arena da esfera pública trazida pela internet e pelas redes sociais. ${ }^{18}$

Aceitando ou não a perspectiva e os diagnósticos dos autores aqui analisados, podemos perceber que as interpretações acerca da Modernidade como racionalização ou esclarecimento, para ficar com o termo usado pelos fundadores da Escola de Frankfurt - sejam elas a denúncia e a crítica a uma Modernidade que é percebida como tragédia, ou a busca pela solução das patologias sociais por meio da construção de uma utopia comunicativa, nos servem como lentes para tentar apreender o que chamamos de Modernidade. Por meio dessas e de outras teorias, percebemos a potencialidade do uso do paradigma da racionalidade para interpretação e inteligibilidade desse tempo tão complexo e cheio de mudanças e incertezas que se convencionou chamar de Modernidade.

\footnotetext{
${ }^{17}$ A despeito do debate em relação a emergência ou não de uma pós-modernidade — o que não se propõe aqui debater.

${ }^{18}$ A despeito dos problemas que já são observados e podem advir nesses novos espaços, como a proliferação das fake news e a possibilidade de manipulação da população via redes sociais, por exemplo, a influenciar eleições, podemos perceber também esses espaços como uma nova arena aberta para a ação comunicativa, onde as vozes de grupos antes relegados ao silêncio passam a ressoar e novos repertórios de ação passam a integrar o espaço público. Como exemplo, podemos citar a Primavera Árabe como fenômeno de mobilização proporcionado pela liberdade de circulação de ideias propiciada pelas redes sociais.
} 


\section{Referências}

ADORNO, Theodor W. e HORKHEIMER, Max. Dialética do Esclarecimento. Fragmentos filosóficos. Rio de Janeiro: Zahar, 1985.

CARVALHO, R. O. de. A modernidade nos clássicos da sociologia: percepções acerca do mundo moderno em Tocqueville, Durkheim e Weber, Sociologias Plurais, v.5 n.2, p. 194-211, dez 2019.

DOMINGUES, José Maurício. Teorias sociológicas no século XX. Rio de Janeiro: Civilização Brasileira, 1ª. Edição, 2001.

FERREIRA, Walace. Uma análise revisionista de Adorno e Horkheimer em "A Dialética do Esclarecimento”, CSOnline - Revista Eletrônica de Ciências Sociais, Ano 2, Volume 5, dezembro 2008.

GONÇALVES, Maria Augusta Salin. Teoria da ação comunicativa de Habermas: Possibilidades de uma ação educativa de cunho interdisciplinar na escola, Educação e Sociedade, Vol.20, n.66, Campinas, abril 1999.

HABERMAS. Jürgen. O discurso filosófico da modernidade: doze lições. São Paulo: Martins Fontes. 2000.

Teoria do Agir Comunicativo. São Paulo: Martins Fontes, 2012.

Direito e democracia: entre a facticidade e validade, vol I, trad. Flávio Beno Siebeneichler. Rio de Janeiro: Tempo Brasileiro, 1997.

NOBRE, Marcos. (Org.). Curso Livre de Teoria Crítica. Campinas: Papirus, 2008.

PIERUCCI, A. F. O Desencantamento do mundo: Todos os passos do conceito em Max Weber. São Paulo: Editora 34, 2003.

SELL, Carlos Eduardo. Max Weber e a racionalização da vida. Petrópolis: Vozes, 2013.

WEBER, Max. A ética protestante e o “espírito" do capitalismo. São Paulo: Companhia das Letras, 2004.

Ciência e política, duas vocações. São Paulo, Cultrix, 2010. 